\title{
Lipid and Alzheimer's disease genes associated with healthy aging and longevity in healthy oldest-old
}

\author{
Lauren C. Tindale ${ }^{1,2}$, Stephen Leach ${ }^{1}$, John J. Spinelli3,4 and Angela R. Brooks- \\ Wilson ${ }^{1,2}$ \\ ${ }^{1}$ Canada's Michael Smith Genome Sciences Centre, British Columbia Cancer Agency, Vancouver, B.C., Canada \\ 2 Department of Biomedical Physiology and Kinesiology, Simon Fraser University, Burnaby, B.C., Canada \\ ${ }^{3}$ Cancer Control Research, British Columbia Cancer Agency, Vancouver, B.C., Canada \\ ${ }^{4}$ School of Population and Public Health, University of British Columbia, Vancouver, B.C., Canada \\ Correspondence to: Angela R. Brooks-Wilson, email: abrooks-wilson@bcgsc.ca \\ Keywords: healthy aging, longevity, Alzheimer's disease, APOE, buffering, epistasis, Gerotarget \\ Received: August 24, $2016 \quad$ Accepted: January 08, $2017 \quad$ Published: February 11, 2017
}

\section{ABSTRACT}

Several studies have found that long-lived individuals do not appear to carry lower numbers of common disease-associated variants than ordinary people; it has been hypothesized that they may instead carry protective variants. An intriguing type of protective variant is buffering variants that protect against variants that have deleterious effects. We genotyped 18 variants in 15 genes related to longevity or healthy aging that had been previously reported as having a gene-gene interaction or buffering effect. We compared a group of 446 healthy oldest-old 'Super-Seniors' (individuals $\mathbf{8 5}$ or older who have never been diagnosed with cancer, cardiovascular disease, dementia, diabetes or major pulmonary disease) to 421 random populationbased midlife controls. Cases and controls were of European ancestry. Association tests of individual SNPs showed that Super-Seniors were less likely than controls to carry an APOEE4 allele or a haptoglobin HP2 allele. Interactions between APOE/ FOXO3, APOE/CRYL1, and LPA/CRYL1 did not remain significant after multiple testing correction. In a network analysis of the candidate genes, lipid and cholesterol metabolism was a common theme. APOE, HP, and CRYL1 have all been associated with Alzheimer's Disease, the pathology of which involves lipid and cholesterol pathways. Age-related changes in lipid and cholesterol maintenance, particularly in the brain, may be central to healthy aging and longevity.

\section{INTRODUCTION}

Healthy aging is the ability to age successfully without succumbing to disease, with an emphasis on healthspan over lifespan [1]. The genetics of healthy aging and longevity is complex, with few genetic associations replicating between studies. APOE (apolipoprotein E) is an exception; genetic variation in this gene has been associated with longevity in multiple genome-wide association studies (GWAS) and candidate gene studies $[1,2]$. The $A P O E \varepsilon 4$ allele is associated with increased mortality, and is also the major genetic risk factor for late onset Alzheimer's disease (AD). While the $\varepsilon 4$ allele is neither necessary nor sufficient for developing the disease, it increases risk in a dose-dependent manner [3].
Long-lived individuals have been found to carry a burden of disease-associated variants comparable to that observed in typical individuals [4-6]. One possible explanation for their ability to remain in good health to advanced ages, and still carry deleterious variants, is the concept of genetic buffering. Genetic buffering is a type of epistatic interaction in which a favourable genotype attenuates the effect of one or more deleterious variants. In this model, long-lived individuals may carry harmful (buffered) variants without developing disease, as a result of also carrying protective (buffering) variants. In a paper first suggesting the application of buffering to human longevity, Bergman and colleagues used changes in allele frequencies with age to show buffering of a deleterious $L P A$ heterozygote by a buffering $C E T P V V$ genotype [7] in participants in the Longevity Genes Project [8]. 
Table 1: Candidate genes and candidate epistatic variants.

\begin{tabular}{|c|c|c|c|c|}
\hline Gene & ID & Effect & Proposed Interaction & Reference \\
\hline APOA1 & rs670 & Deleterious & Buffered & Garasto et al., 2003 [45] \\
\hline$A P O E$ & APOE 44 & Deleterious & $A P O E \varepsilon 4$ buffered by $H P 1 / 1$ & Napolioni et al., 2011 [44] \\
\hline$H F E$ & rs 1800562 & Deleterious & $H F E$ T allele buffered & Tan et al., 2003 [24] \\
\hline$K L$ & rs9536314 & Deleterious & KL het buffered & Bergman et al., 2007 [7] \\
\hline$L P A(1)$ & rs1853021 & Deleterious & LPA het buffered by CETP VV & Bergman et al., 2007 [7] \\
\hline$L P A(2)$ & rs3798220 & Deleterious & Risk for coronary disease & Clarke et al., 2009 [22] \\
\hline$L P A(3)$ & rs 10455872 & Deleterious & Risk for coronary disease & Clarke et al., 2009 [22] \\
\hline MTTP & rs2866164 & Deleterious & $\begin{array}{l}\text { MTTP CC buffered by } A P O C 3 C C, \\
C E T P V V, A D I P O Q \text { del/del }\end{array}$ & Huffman et al., 2012 [46] \\
\hline PON1 & rs662 & Deleterious & PON1 het buffered & Bonafè et al., 2002 [47] \\
\hline$A D I P O Q$ & rs56354395 & Protective & ADIPOQ del/del buffers MTTP CC & Atzmon et al., 2008 [27] \\
\hline APOC 3 & $\begin{array}{l}\text { rs595049 (LD with } \\
\text { rs2542052) }\end{array}$ & Protective & APOC3 CC buffers $M T T P C C$ & Atzmon et al., 2006 [48] \\
\hline CETP & rs5882 & Protective & $\begin{array}{l}\text { CETP VV buffers MTTP CC, LPA(1) } \\
\text { het }\end{array}$ & Barzilai et al., 2003 [29] \\
\hline CRYL1 & rs7989332 & Protective & AD-associated with $K H D R B S 2$ & Gusareva et al., 2014 [15] \\
\hline FOXO1 & rs2701858 & Protective & $\begin{array}{l}\text { Joint effect with } F O X O 3(1) \text { for } \\
\text { longevity }\end{array}$ & Tan et al., 2013 [49] \\
\hline FOXO3(1) & rs9486902 & Protective & $\begin{array}{l}\begin{array}{l}\text { Joint effect with } F O X O 1 \text { for } \\
\text { longevity }\end{array} \\
\end{array}$ & Tan et al., 2013 [49] \\
\hline$F O X O 3(2)$ & rs2802292 & Protective & FOXO3 $G G$ buffering & Willcox et al., 2008 [20] \\
\hline$H P$ & rs72294371 & Protective & $H P 1 / 1$ buffers $A P O E \varepsilon 4$ & Napolioni et al., 2011 [44] \\
\hline KHDRBS2 & rs6455128 & Protective & AD-associated with $C R Y L 1$ & Gusareva et al., 2014 [15] \\
\hline
\end{tabular}

Effect indicates whether the variant was considered be deleterious or protective in the original literature report. Het $=$ heterozygous, $\mathrm{AD}=$ Alzheimer's disease.

We have assembled a list of genetic variants previously reported as having possible epistatic or buffering/buffered effects related to longevity in human studies. We examined these variants in individuals aged 85 years or older who had never been diagnosed with cancer, cardiovascular disease (CVD), diabetes, dementia, or major pulmonary disease; we call them the 'Super-Seniors' [9]. These healthy oldest-old were compared to random population-based middle-aged controls. We hypothesize that epistatic interactions, in which longevity-promoting buffering variants protect against the effects of deleterious buffered variants, contribute to the Super-Seniors' health and longevity.

\section{RESULTS}

\section{Candidate variants}

A search in PubMed of the combinations "epistasis AND aging", "epistasis AND longevity", "buffering AND aging", "buffering AND longevity", "human", and "genetics" produced a list of 111 papers of interest. Manual review of the papers and, in some cases, references cited within them, identified 18 variants in 15 genes suspected as having an interaction related to aging or longevity
(Table 1). This included 15 SNPs, a 1bp deletion, a 1724bp deletion, and the well-characterized $A P O E$ haplotype.

\section{Genotypes and quality control}

After excluding 11 samples with a call rate $<90 \%$, there were 459 (152 male, 307 female) Super-Seniors and 417 (166 male, 251 female) controls. The haptoglobin $(H P)$ variant genotyped by PCR had a call rate of $93 \%$. SNP call rates all exceeded 95\%. LPA SNP rs3798220 had a minor allele frequency (MAF) $<5 \%$ in our study population so was excluded from analysis. There were no significant deviations from Hardy-Weinberg Equilibrium in controls when corrected using false discovery rate.

\section{Association tests of individual variants}

There was a greater proportion of female SuperSeniors [odds ratio (OR) 1.33, 95\% confidence interval $(\mathrm{CI})=1.01-1.76]$, so sex was included in all models. Genotype frequencies for all variants are shown in Table 2 . When the 17 variants were tested for association with healthy aging, under dominant and additive models, only the $H P$ and $A P O E$ variants showed significant associations (Table 3 and Table S1). 
Table 2: Genotype counts and frequencies in Super-Seniors and controls.

\begin{tabular}{|c|c|c|c|c|c|c|c|c|c|c|c|}
\hline \multirow[b]{2}{*}{ Gene } & \multirow[b]{2}{*}{ ID } & \multirow[b]{2}{*}{ Alleles* } & \multirow[b]{2}{*}{$\begin{array}{l}\text { MAF in } \\
\text { study }\end{array}$} & \multirow[b]{2}{*}{$\begin{array}{c}\text { MAF } \\
\text { in 1000 } \\
\text { Genomes }\end{array}$} & \multirow[b]{2}{*}{$\begin{array}{l}\text { GRGh38 genomic } \\
\text { location }\end{array}$} & \multicolumn{3}{|c|}{ Super-Seniors } & \multicolumn{3}{|c|}{ Controls } \\
\hline & & & & & & \begin{tabular}{|l|} 
Homo \\
major \\
allele
\end{tabular} & Het & \begin{tabular}{|l|} 
Homo \\
minor \\
allele
\end{tabular} & \begin{tabular}{|l|}
$\begin{array}{l}\text { Homo } \\
\text { major } \\
\text { allele }\end{array}$ \\
\end{tabular} & Het & \begin{tabular}{|l} 
Homo \\
minor \\
allele
\end{tabular} \\
\hline$A D I P O Q$ & rs56354395 & $\mathrm{A}>\mathrm{del}$ & 0.370 & 0.499 & $3: 186855076 / 5$ & 182 & 212 & 54 & 159 & 192 & 63 \\
\hline$A P O A 1$ & rs670 & $\mathrm{C}>\mathrm{T}$ & 0.158 & 0.188 & $11: 116837697$ & 308 & 123 & 8 & 283 & 110 & 8 \\
\hline$A P O C 3$ & rs595049 & $\mathrm{T}>\mathrm{G}$ & 0.345 & 0.498 & $11: 116828729$ & 204 & 196 & 59 & 176 & 191 & 50 \\
\hline$A P O E$ & APOE 4 & $\varepsilon 2 / \varepsilon 3>\varepsilon 4$ & 0.128 & & & 365 & 84 & 4 & 293 & 109 & 10 \\
\hline CETP & rs5882 & $\mathrm{T}>\mathrm{C}$ & 0.304 & 0.466 & $16: 56982180$ & 209 & 190 & 44 & 198 & 171 & 32 \\
\hline CRYL1 & rs7989332 & $\mathrm{G}>\mathrm{T}$ & 0.261 & 0.222 & $13: 20476436$ & 249 & 179 & 30 & 224 & 169 & 24 \\
\hline FOXO1 & rs2701858 & $\mathrm{G}>\mathrm{A}$ & 0.065 & 0.108 & $13: 40564252$ & 388 & 63 & 2 & 371 & 41 & 2 \\
\hline $\mathrm{FOXO3}$ & rs9486902 & $\mathrm{C}>\mathrm{T}$ & 0.142 & 0.174 & 6:108556849 & 341 & 100 & 13 & 305 & 97 & 12 \\
\hline $\mathrm{FOXO3}$ & rs2802292 & $\mathrm{A}>\mathrm{C}$ & 0.366 & 0.469 & $6: 108587315$ & 162 & 226 & 55 & 166 & 189 & 47 \\
\hline HFE & rs1800562 & $\mathrm{C}>\mathrm{T}$ & 0.067 & 0.013 & 6:26092913 & 394 & 64 & 1 & 367 & 49 & 1 \\
\hline$H P$ & rs72294371 & $H P 2>H P 1$ & 0.448 & & & 126 & 199 & 99 & 123 & 202 & 63 \\
\hline KHDRBS2 & rs6455128 & $\mathrm{C}>\mathrm{A}$ & 0.178 & 0.219 & $6: 61987841$ & 321 & 117 & 21 & 279 & 122 & 16 \\
\hline$K L$ & rs9536314 & $\mathrm{T}>\mathrm{G}$ & 0.163 & 0.130 & $13: 33054001$ & 334 & 114 & 11 & 283 & 116 & 17 \\
\hline$L P A$ & rs 1853021 & $\mathrm{C}>\mathrm{T}$ & 0.152 & $\mathrm{n} / \mathrm{a}$ & $6: 160664263$ & 324 & 119 & 9 & 303 & 96 & 15 \\
\hline$L P A$ & rs 3798220 & $\mathrm{~T}>\mathrm{C}$ & 0.017 & 0.051 & 6:160540105 & 445 & 14 & 0 & 402 & 15 & 0 \\
\hline$L P A$ & rs10455872 & $\mathrm{T}>\mathrm{C}$ & 0.070 & 0.022 & 6:160589086 & 403 & 54 & 2 & 357 & 56 & 4 \\
\hline MTTP & rs2866164 & $\mathrm{C}>\mathrm{G}$ & 0.256 & 0.250 & 4:99569786 & 234 & 168 & 30 & 229 & 137 & 29 \\
\hline PON1 & rs662 & $A>G$ & 0.284 & 0.457 & 7:95308134 & 228 & 177 & 38 & 212 & 151 & 37 \\
\hline
\end{tabular}

*Major allele $>$ minor allele. Minor allele frequency (MAF) was calculated from the entire study population.

Table 3: Odds ratios and $95 \%$ confidence intervals for the association between variants in $A P O E$ and $H P$ and healthy aging.

\begin{tabular}{|c|c|c|c|c|c|c|}
\hline \begin{tabular}{|l|} 
Variant \\
\end{tabular} & Model & Super-Seniors & Controls & Genotype & Odds ratio $(95 \% \mathrm{CI})$ & $p$ value \\
\hline \multirow{5}{*}{ HP rs72294371 } & \multirow{2}{*}{ Dominant } & 99 & 63 & $1 / 1$ & 1 & 0.010 \\
\hline & & 325 & 325 & $1 / 2$ or $2 / 2$ & $0.63(0.44-0.90)$ & $(\mathrm{df}=1)$ \\
\hline & \multirow{3}{*}{ Additive } & 99 & 63 & $1 / 1$ & 1 & \multirow{3}{*}{$\begin{array}{l}0.056 \\
(\mathrm{df}=1)\end{array}$} \\
\hline & & 199 & 202 & $1 / 2$ & $0.62(0.43-0.90)$ & \\
\hline & & 126 & 123 & $2 / 2$ & $0.64(0.42-0.96)$ & \\
\hline \multirow{7}{*}{$A P O E$ haplotype } & $\varepsilon 4$ Dominant & $\begin{array}{l}365 \\
88\end{array}$ & $\begin{array}{l}293 \\
119\end{array}$ & $\begin{array}{l}\text { Non- } \varepsilon 4 \text { carrier } \\
\varepsilon 4 \text { carrier }\end{array}$ & $\begin{array}{l}1 \\
0.59(0.43-0.81)\end{array}$ & $\begin{array}{l}0.0010 \\
(\mathrm{df}=1)\end{array}$ \\
\hline & \multirow{6}{*}{ Overall } & 283 & 248 & $\varepsilon 3 / \varepsilon 3$ & 1 & \multirow{6}{*}{$\begin{array}{l}0.00017 \\
(\mathrm{df}=5)\end{array}$} \\
\hline & & 18 & 3 & $\varepsilon 2 / \varepsilon 2$ & $5.33(1.55-18.34)$ & \\
\hline & & 64 & 42 & $\varepsilon 2 / \varepsilon 3$ & $1.32(0.86-2.02)$ & \\
\hline & & 77 & 94 & $\varepsilon 3 / \varepsilon 4$ & $0.71(0.50-1.01)$ & \\
\hline & & 7 & 15 & $\varepsilon 2 / \varepsilon 4$ & $0.40(0.16-1.00)$ & \\
\hline & & 4 & 10 & $\varepsilon 4 / \varepsilon 4$ & $0.35(0.11-1.12)$ & \\
\hline
\end{tabular}

Super-Seniors were less likely than controls to carry the known disease risk alleles $H P 2$ or $A P O E \varepsilon 4$. Carriers of the HP2 allele had decreased odds of being a SuperSenior, OR 0.63 (95\% CI $=0.44-0.90, p=0.010)$, as did APOE\&4 allele carriers, OR $0.59(95 \% \mathrm{CI}=0.43-0.81, p$ $=0.0010)$. The significance of the association with HP did not hold under application of the false discovery rate (FDR) (threshold $=0.05$ for 17 comparisons), but $A P O E$ remained significant after FDR, $p=0.017$.

Using an additive model, $H P$ genotype was associated with healthy longevity with a per allele OR of $0.83(95 \% \mathrm{CI}=0.68-1.00, p=0.056)$. Compared to
HP1 homozygotes, heterozygotes had an OR of 0.62 (95\% CI $=0.43-0.90)$ and HP2 homozygotes had an OR of 0.64 (95\% CI $=0.42-0.96)$. Super-Senior status also differed significantly by $A P O E$ haplotype using an overall model with a per allele OR of $0.76(95 \% \mathrm{CI}=0.67$ $0.87, p=0.00017)$. Compared to $A P O E \varepsilon 3 / 3, A P O E \varepsilon 2 / 2$ was associated with increased odds for healthy aging, $\mathrm{OR}=5.33(95 \% \mathrm{CI}=1.55-18.34)$, and $A P O E \varepsilon 3 / 4$ and $A P O E \varepsilon 2 / 4$ did not reach significance against healthy aging with odds ratios of $0.71(95 \% \mathrm{CI}=0.50-1.01)$ and 0.40 $(95 \% \mathrm{CI}=0.16-1.00)$, respectively. 
Table 4: The top 20 functions and diseases represented in a candidate gene network in IPA ${ }^{\circledR}$.

\begin{tabular}{|l|l|}
\hline Rank & Diseases and Functions \\
\hline 1 & Disorder of lipid metabolism \\
\hline 2 & Dyslipidemia \\
\hline 3 & Concentration of sterol \\
\hline 4 & Quantity of steroid \\
\hline 5 & Concentration of triacylglycerol \\
\hline 6 & Concentration of lipid \\
\hline 7 & Atherosclerosis \\
\hline 8 & Metabolism of triacylglycerol \\
\hline 9 & Concentration of cholesterol \\
\hline 10 & Hyperlipoproteinemia \\
\hline 11 & Hyertriglyceridemia \\
\hline 12 & Area of atherosclerotic lesion \\
\hline 13 & Accumulation of lipid \\
\hline 14 & Size of atherosclerotic lesion \\
\hline 15 & Efflux of cholesterol \\
\hline 16 & Homeostasis of lipid \\
\hline 17 & $\begin{array}{l}\text { Concentration of cholesterol } \\
\text { ester }\end{array}$ \\
\hline 18 & Hyperlipidemia \\
\hline 19 & Dementia \\
\hline 20 & Transport of lipid \\
\hline
\end{tabular}

\section{Gene-gene interaction analysis}

Among 7 previously reported gene-gene interactions, using an additive-additive model we did not observed any significant interactions (Table S2). The interaction term between rs6455128 in KHDRBS2 (KH domain containing, RNA binding, signal transduction associated 2) and rs7989332 in CRYL1 (crystallin lambda 1), however, was $p=0.077$. Because the original rs6455128/rs7989332 interaction was found in a genomewide association interaction analysis for $\mathrm{AD}$, we adjusted for $A P O E \varepsilon 4$ carrier status and found that the p-value for the interaction decreased slightly $(p=0.061)$. Odds ratios for individual genotypes are shown in Table S3. Per genotype, it appears that there may be an interaction between CRYL1 GG and KHDRBS2 AC/AA.

Since most variants did not have a known interaction partner, we then tested for interactions between all combinations of the nine protective and eight deleterious variants (72 interaction tests) using an additive-additive model. Sex was included in all models. Three additional variant pairs showed evidence of interactions. $A P O E$ haplotype and rs9486902 in $\mathrm{FOXO} 3$ (forkhead box O3) had a significant interaction ( $p=0.035)$, as did $\mathrm{rs} 10455872$ in LPA (lipoprotein(a)) and rs7989332 CRYL1 $(p=0.041)$. $A P O E$ haplotype also showed evidence of an interaction with rs7989332 CRYL1 $(p=0.049)$. No interactions withstood FDR correction. Odds ratios for individual genotypes in interacting pairs are shown in Tables S4-S6; due to low frequencies only $A P O E 4$ carrier vs. non-carrier status, CRYL1/LPA and CRYL1/KHDRBS2 dominant models are presented. There is some evidence that the APOE4 allele interacts with the rs9486902 FOXO3 CC genotype, as well as the rs7989332 CRYL1 GG and GT genotypes.

There were also two pairs of SNPs with possible interactions. Rs1853021 in LPA and rs2802292 in FOXO3 ( $p=0.052$ ) and rs 1800562 in HFE (hemochromatosis) and rs56354395 in ADIPOQ (adiponectin, C1Q and collagen domain containing) $(p=0.059)$.

\section{Network analysis}

Network analysis was done using QIAGEN's Ingenuity ${ }^{\circledR}$ Pathway Analysis (IPA ${ }^{\circledR}$, QIAGEN Redwood City, www.qiagen.com/ingenuity) to characterize the types of genes identified during the literature search. Using the 15 genes from the literature search produced a network that connected 13 of the 15 query genes. The "grow" feature of IPA ${ }^{\circledR}$ was used to expand the network to include additional molecules (Figure 1). When growing the network, priority is given to molecules that have the most overlap with the parts of the existing network that are the least connected. Of note, KHDRBS 2 and CRYL1 did not have a known network connection with each other; however, CRYL1 was connected to $A P O E$ by one node. $A P O E$ was also connected by one node to $F O X O 3$, which was connected by one node to $L P A$. HFE and $A D I P O Q$ were connected by a single edge.

The top functional and disease category represented in this network was metabolic disease, followed by hematological disease, lipid metabolism, and molecular transport. Multiple pathways are related to the genes in this network; the top 20 functions and diseases of those pathways are listed in Table 4; all of the top terms relate to lipids or cholesterol.

\section{DISCUSSION}

$A P O E$ has three major alleles: $\varepsilon 2$ has been associated with decreased mortality [10, 11], $\varepsilon 3$ can be considered neutral, and $\varepsilon 4$ is associated with increased risk of AD and mortality [3]. Super-Seniors were less likely to carry an $A P O E \varepsilon 4$ allele, a finding that we previously published [12]. The APOE $\varepsilon 2 / 2$ diplotype was protective. A larger sample size would be needed to more confidently determine the effects of other diplotypes.

The $H P 2$ allele contains a duplication of exons 3 and 4 of the haptoglobin gene [13], making the HPl and $H P 2$ alleles functionally different. Although the inverse association of $H P 2$ carrier status with healthy aging was not significant after FDR correction, it is consistent with the idea that the $H P 1 / 1$ genotype is associated with longevity [14]. 
Several gene-gene interaction tests gave results that approached but did not achieve statistical significance. While we cannot reject the null hypothesis of no interaction in these cases, they represent candidate pairs with potentially intriguing biological roles that would be worth testing in other studies. One such pair is rs6455128 in KHDRBS2 and rs7989332 in CRYL1, previously associated with AD [15]. Gusareva et al. hypothesized that the CRYL1 encoded crystallin protein may act as a stressprotective heat-shock protein that could have a functional interaction with KHDRBS2, which also has a potential role in response to stress [15]. Gusareva et al. postulated that this interaction may occur within the TOR pathway [16], which influences $\beta$-amyloid plaques $(A \beta)$ and $A D$ like deficits in a mouse model [17] and life span in model organisms $[18,19]$.

Some interactions between all combinations of variants were significant prior to multiple testing correction and may therefore be candidates for future replication analyses. APOE haplotype and rs9486902 in FOXO3 showed an interaction effect. Per genotype, there may be an interaction between the $A P O E 4$ allele and the FOXO3 $C C$ genotype; $F O X O 3 C C$ could be a buffering genotype for the deleterious APOE4. Pathway analysis in $\mathrm{IPA}^{\circledR}$ showed that one mechanism of interaction could be through amyloid beta precursor protein, APP. FOXO3 is part of the insulin/insulin-like growth factor 1 signal pathway and has been associated with longevity [20], and FoxO proteins have been implicated in AD [21].

$A P O E$ haplotype and $L P A$ rs10455872 had significant interaction effects with rs7989332 in CRYL1. The interaction between $A P O E$ and CRYL1 may originate from an interaction between the APOE4 allele and the CRYL1 GG and GT genotypes. Interestingly, the CRYL1 GG genotype also showed evidence of an interaction with the $K H D R B S 2$ AC/AA genotypes.

Another example is rs1853021 in LPA, which showed $p=0.052$ for interaction with rs2802292 in FOXO3. Rs 1853021 has been associated with elevated $\mathrm{Lp}$ (a) lipoprotein level, which is a risk factor for coronary disease, carotid atherosclerosis, and stroke [22]. Rs2802292 has been associated with longevity [20] and all-cause mortality [23].

Rs1800562 in HFE and rs56354395 in ADIPOQ ( $p$ $=0.059)$ were connected by a single edge in $\mathrm{IPA}^{\circledR}$. The minor allele in HFE rs1800562 has been associated with risk of death, but has been seen to increase in frequency at older ages [24]. Increased serum adiponectin levels have

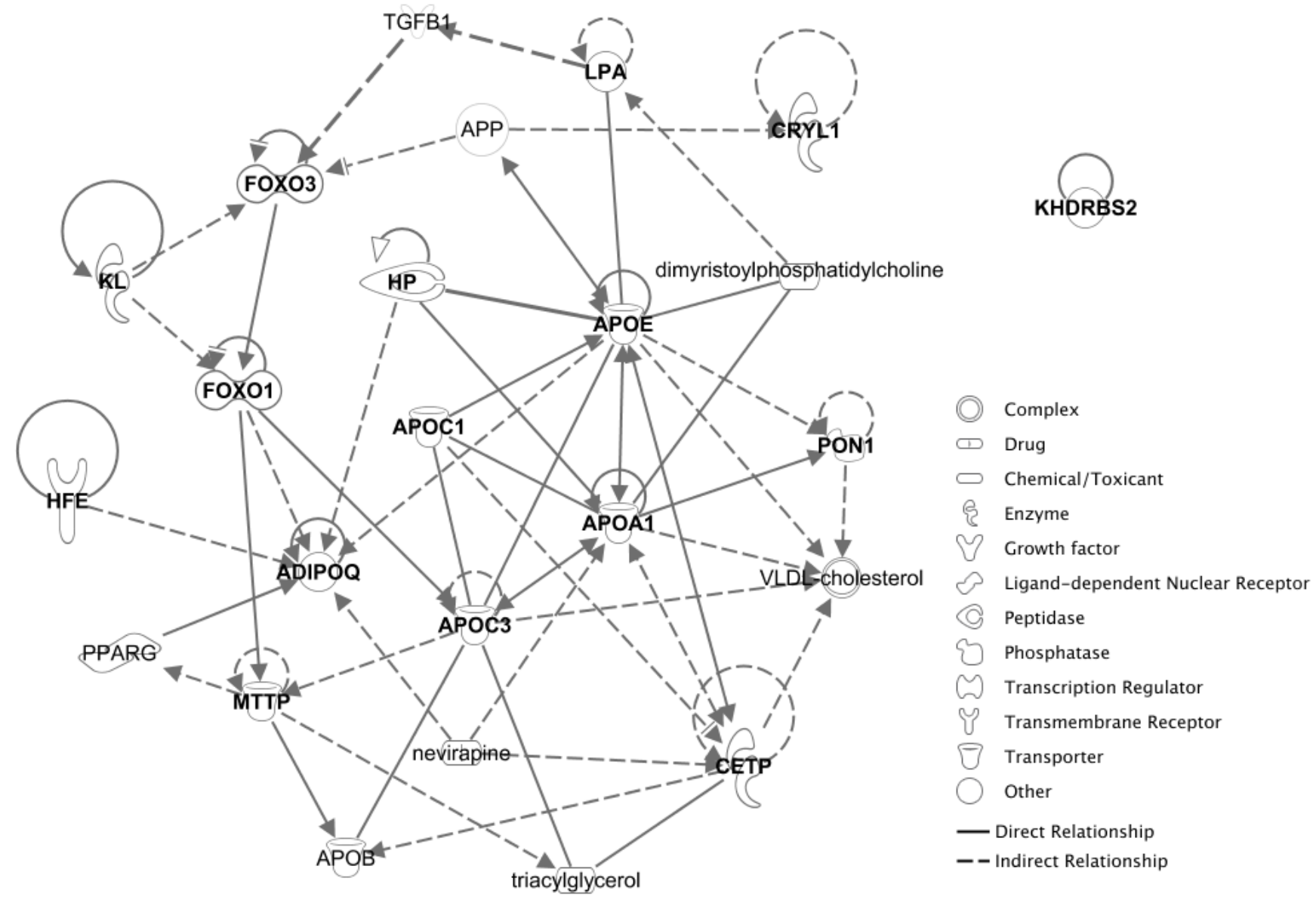

Figure 1: A network including 15 candidate epistatic longevity genes. The diagram was created using QIAGEN's Ingenuity ${ }^{\circledR}$ Pathway Analysis software. 
been associated with longevity $[25,26]$. Two variants in $A D I P O Q$, including rs56354395, have been associated with increased adiponectin levels and the del/del genotype had a higher prevalence in long-lived men [27].

When looking at the overall network, metabolic disease, hematological disease, lipid metabolism, and molecular transport were the most represented functional and disease categories. Despite the fact that many of the individual genes did not show significant differences in our population, it is interesting that lipid and cholesterol functions were significantly over-represented in the network. As well, a review of GWAS-identified risk genes for $\mathrm{AD}$ found that the associated genes clustered into three pathways: cholesterol and lipid metabolism, immune system and inflammatory response, and endosome vesicle cycling [28]. The idea that longevity is associated with a favourable lipid profile is not new. It has been found that individuals with exceptional longevity and their offspring have HDL and LDL particle sizes that are significantly larger than controls [29], that offspring of centenarians have favourable lipid profiles compared to their spouse controls [8], and that favourable HDL phenotypes and genotypes may contribute to a lower incidence of agerelated diseases such as CVD and decreased mortality [30]. These results are all consistent with lipid and cholesterol maintenance being a key mediator in healthy aging and longevity.

Many of the candidate genes in our study were chosen in the literature reports by the original investigators due to their potential function in longevity. As a result, the selection of genes is biased; however, it is still valuable to examine themes, especially among the genes that were also significant in our study population, which represents long-term good health more than extreme longevity.

CVD and AD are age-related chronic diseases that decrease quality of life and increase risk of mortality. $A P O E \varepsilon 4$ confers a dose dependent increased risk for developing $\mathrm{AD}$ [3], and it was found in a meta-analysis that while the global frequency of the $\varepsilon 4$ allele is $13.7 \%$, the allele frequency in $\mathrm{AD}$ patients is $36.7 \%$ [31]. $A P O E \& 4$ is also associated with hyperlipidemia and hypercholesterolemia, and causes neuroinflammation resulting in neurovascular dysfunction [32].

The two main neuropathological features seen in the brains of patients with $\mathrm{AD}$ are $\mathrm{A} \beta$ and neurofibrillary tangles [3]. ApoE is thought to help to remove $A \beta$ from the brain by transporting it across the blood brain barrier; however, ApoE4 lipoproteins have a decreased binding affinity for $\mathrm{A} \beta$ compared to ApoE3 lipoproteins and may therefore be less efficient. ApoE also mediates delivery of cholesterol to neurons in the CNS, which is less efficient by ApoE4 than ApoE3 [32]. The CNS contains about $25 \%$ of total body cholesterol, which plays a key role in synaptic plasticity [33]. With age, there are systemwide changes in cholesterol metabolism, and this altered metabolism in the brain may relate to $\mathrm{AD}$ development
[33]. There is also a decreased amount of cholesterol in the hippocampus and cortical areas in $\mathrm{AD}$ patients compared to age-matched controls [32].

Cardiovascular and neurovascular health share common risk factors including diabetes mellitus and hypertension [34]. Cognitively normal individuals with controlled hypertension have less $\mathrm{A} \beta$ accumulation than those with unmedicated hypertension. As well, the combination of carrying an $A P O E \varepsilon 4$ allele and having unmedicated hypertension increased the risk for $A \beta$ accumulation [34].

$\mathrm{Hp}$ is an extracellular chaperone that acts as an antioxidant and anti-inflammatory by binding free hemoglobin, which it then transports to the liver [35]. Hp is produced in the brain in response to stress stimuli; it is increased in the cerebral spinal fluid of patients with $\mathrm{AD}$ and other neurodegenerative disorders [36]. Patients with AD consistently show signs of inflammation in their brains and oxidative stress is strongly implicated in $\mathrm{AD}$ etiology [35]. Hp has been found to be more oxidized in $\mathrm{AD}$ patients, and in vitro, oxidized Hp is less able to perform its chaperone function and inhibit $A \beta$ aggregates $[36,37]$. $A \beta$ also competes with hemoglobin for binding to $\mathrm{Hp}$, thus impairing its antioxidant function [36]. There is strong support that $A \beta$ is central in $A D$ pathogenesis and it is thought to trigger oxidative stress-mediated damage that leads to neuronal death [37].

$H P 1$ and $H P 2$ alleles form structurally different proteins that differ in hemoglobin binding and antioxidant capacity, and may be related to autoimmune and inflammatory disorders [38]. Despite the association of $H P 1 / 1$ with longevity, there are conflicting results from studies looking at $H P$ in relation to coronary heart disease (CHD) [39-41].

Our findings provide further evidence that $A P O E$ and genes in associated pathways are key players in healthy aging. This is consistent with a recent informed GWAS that utilized knowledge about age-related diseases to identify new extreme longevity loci that overlap with those associated with coronary artery disease and AD [42]. As well, in a whole genome sequencing study in a healthy aging cohort aged over 80 years, the Topol and Torkamani group found that healthy aging is associated with reduced genetic susceptibility to $\mathrm{AD}$ and coronary artery disease, but not cancer or diabetes [43]. In addition to $A P O E$ being the most replicable signal in GWAS of longevity, the search for more complex longevity haplotypes and interactions points towards mechanisms related to $A P O E$, $\mathrm{AD}$, and lipids.

Our results highlight pathways related to $\mathrm{AD}$ and reinforce the importance of lipids and cholesterol in healthy aging and longevity. Due to the exploratory nature of finding epistatic effects, it is unsurprising that the observed effects do not remain significant after multiple testing correction. However, these results are noteworthy as they represent additional candidates for buffering 
pairs that may be tested in other studies. The study of epistatic interactions, particularly buffering/ buffered pairs, is important as the identification of such pairs may help identify therapeutic drug targets for use in aiding individuals who do not carry health-protective longevity variants.

\section{MATERIALS AND METHODS}

\section{Subjects}

The current analysis included 466 Super-Seniors (female $=312$, male $=154 ;$ mean $=88.6$ years, $\mathrm{SD}=3.0$, range $=85-108$ years), and 421 mid-life controls (female $=253$, male $=168$; mean $=46.8$ years, $\mathrm{SD}=3.3$, range $=$ $40-54$ years) $[9,12]$. The Super-Senior group included 140 subjects 90 years and older, 4 of whom were centenarians. Both groups of unrelated individuals were of European ancestry and lived in Metro Vancouver, British Columbia (BC), Canada. Controls were random and populationbased, and recruited randomly from BC Medical Services Plan lists. Research ethics board approval was received from the joint Clinical Research Ethics Board of the BC Cancer Agency and the University of British Columbia and Simon Fraser University. All subjects gave written informed consent.

\section{Literature search}

A literature search for protective buffering and deleterious buffered variants, as well as other epistatic effects associated with longevity was performed in PubMed. PubMed was chosen because of its biomedical and clinical focus. Search terms included combinations of: buffering, epistasis, aging, longevity, human, and genetics. Only variants found in human studies were considered. Variants located in the same gene were verified not to be in linkage disequilibrium at a threshold of $r^{2}>0.8$.

\section{Genotyping}

Sixteen SNPs were genotyped using Sequenom (San Diego, USA) iPLEX Gold technology at the McGill University and Genome Quebec Innovation Center. Two markers with a call rate below $95 \%$ were re-genotyped by the same method. 11 samples with a call rate $<90 \%$ across all markers were excluded. Three markers that could not be genotyped by the Sequenom method were either replaced by another marker in linkage disequilibrium (rs2542052 in $L P A)$ or genotyped by $\operatorname{TaqMan}^{\circledR}$ (rs56354395 in $A D I P O Q)$ or PCR (rs72294371 in HP). Custom TaqMan ${ }^{\circledR}$ probes were designed using the Thermo Fisher Scientific (Waltham, USA) online tool (www.thermofisher.com).
A 1724 bp insertion in HP was genotyped by PCR using a two primer design as described by Koch et al. [13]; products were sized on an agarose gel. The first primer set: 5'-AGCCCACCCCTCCACCTATGTGCC-3' and 5'-GCTTAAGATCCCAGTCGCATACC-3' [44], yielded a 3221 or $4945 \mathrm{bp}$ product, corresponding to the HP1 allele and HP2 allele, respectively. Because the larger HP2 product was not always clearly visible when the gel was imaged, a second set of primers was used to detect this allele. The second primer set: 5'-CCCAGCCTCTTCTGCTCTTA-3' and 5'-TGCACATCAATCTCCTTCCA-3' yielded a 248bp product only when the $H P 2$ allele was present.

\section{Association tests of individual variants}

Analyses were performed in $\mathrm{R}$ 3.2.2. Individual variants were tested using logistic regression to estimate odds ratios and $95 \%$ confidence intervals for associations between Super-Senior status and variants. Super-Seniors and controls were coded as 1 and 0 . Models were adjusted for sex. Dominant and additive models were tested. In the dominant model, the major allele homozygote was coded as 0 , and the heterozygote and minor allele homozygote were both coded as 1. Exceptions to this were $A P O E$ and $H P$, which were coded for the presence of carrying the riskassociated $A P O E \varepsilon 4$ allele and $H P 2$ allele, respectively. In the additive model, genotypes were coded as $0,1,2$. All $p$ values were determined using the likelihood ratio test. The false discovery rate $(\mathrm{FRD}$ threshold $=0.05$ ) was used to adjust for multiple comparisons.

\section{Gene-gene interaction analysis}

Gene-gene interactions were tested using an additive-additive model. Logistic regression analysis was conducted as follows: $y \sim$ variant $1+$ variant $2+$ variant 1 $x$ variant $2+\operatorname{sex}($ function $=$ glm, family $=$ binomial, link $=$ logit). Super-Senior/control status was the outcome variable.

First, the 7 epistatic pairs from the literature were independently tested to see if they were observed in our population. Then all combinations of putative protective and deleterious variants were compared. FDR was used to adjust for multiple comparisons.

\section{Network analysis}

Pathway analysis was conducted using QIAGEN Ingenuity ${ }^{\circledR}$ Pathway Analysis (IPA ${ }^{\circledR}$, QIAGEN Redwood City, www.qiagen.com/ingenuity) to characterize the types of genes identified during the literature search. IPA ${ }^{\circledR}$ uses the curated Ingenuity ${ }^{\circledR}$ Knowledge Base constructed from peer-reviewed journals and biomedical databases 
to construct networks of connections between genes and molecules. The 15 genes from the literature search were entered into IPA ${ }^{\circledR}$ to produce a network that was then "grown" to include additional related molecules. IPA ${ }^{\circledR}$ was also used to identify functions and diseases that were most significantly represented in the network.

\section{ACKNOWLEDGMENTS}

We thank the Super-Seniors and controls for their participation.

\section{CONFLICTS OF INTEREST}

No conflicts of interest to declare.

\section{FUNDING}

Collection of the Super-Seniors and controls was supported by a New Emerging Team grant from the Canadian Institutes of Health Research (CIHR). AB-W was a Senior Scholar of the Michael Smith Health Research Foundation. LT holds a CIHR studentship. This research is funded by the Canadian Cancer Society (grant \# 703469).

\section{REFERENCES}

1. Brooks-Wilson AR. Genetics of healthy aging and longevity. Hum Genet. 2013; 132:1323-1338.

2. Beekman M, Blanche H, Perola M, Hervonen A, Bezrukov V, Sikora E, Flachsbart F, Christiansen L, De Craen AJ, Kirkwood TB, Rea IM, Poulain M, Robine JM, et al. Genome-wide linkage analysis for human longevity: Genetics of Healthy Aging Study. Aging Cell. 2013; 12:184-193.

3. Rocchi A, Pellegrini S, Siciliano G and Murri L. Causative and susceptibility genes for Alzheimer's disease: a review. Brain Research Bulletin. 2003; 61:1-24.

4. Stevenson M, Bae H, Schupf N, Andersen S, Zhang Q, Perls TT and Sebastiani P. Burden of disease variants in participants of the long life family study. Aging (Albany NY). 2015; 7:123-32. doi: 10.18632/aging.100724.

5. Beekman M, Nederstigt C, Suchiman HE, Kremer D, van der Breggen R, Lakenberg N, Alemayehu WG, de Craen AJ, Westendorp RG, Boomsma DI, de Geus EJ, HouwingDuistermaat JJ, Heijmans BT, et al. GWAS identified disease risk alleles do not compromise human longevity. Proc Natl Acad Sci U S A. 2010; 107:18046-18049.

6. Tindale LC, Zeng A, Bretherick KL, Leach S, Thiessen $\mathrm{N}$ and Brooks-Wilson AR. Burden of Common Complex Disease Variants in the Exomes of Two Healthy Centenarian Brothers. Gerontology. 2016; 62:58-62.

7. Bergman A, Atzmon G, Ye K, MacCarthy T and Barzilai N. Buffering mechanisms in aging: a systems approach toward uncovering the genetic component of aging. PLoS Comput Biol. 2007; 3:e170.

8. Barzilai N, Gabriely I, Gabriely M, Iankowitz N and Sorkin JD. Offspring of centenarians have a favorable lipid profile. Journal of the American Geriatrics Society. 2001; 49:76-79.

9. Halaschek-Wiener J, Amirabbasi-Beik M, Monfared N, Pieczyk M, Sailer C, Kollar A, Thomas R, Agalaridis G, Yamada S, Oliveira L, Collins JA, Meneilly G, Marra MA, et al. Genetic variation in healthy oldest-old. PLoS One. 2009; 4:e6641.

10. Schupf N, Barral S, Perls T, Newman A, Christensen K, Thyagarajan B, Province M, Rossi WK and Mayeux R. Apolipoprotein E and familial longevity. Neurobiol Aging. 2013; 34:1287-1291.

11. Frisoni GB, Louhija J, Geroldi $\mathrm{C}$ and Trabucchi $\mathrm{M}$. Longevity and the e2 Allele of Apolipoprotein E: The Finnish Centenarians Study. Journal of Gerontology Series A, Biological Sciences and Medical Sciences. 2001; 56:M75-78.

12. Tindale LC, Leach S, Ushey K, Daley D and Brooks-Wilson AR. Rare and common variants in the Apolipoprotein E gene in healthy oldest old. Neurobiol Aging. 2014; 35:727 e721-723.

13. Koch W, Latz W, Eichinger M, Roguin A, Levy AP, Schomig A and Kastrati A. Genotyping of the Common Haptoglobin Hp 1/2 Polymorphism Based on PCR. Clinical Chemistry. 2002; 48:1377-1382.

14. Napolioni V, Gianni P, Carpi FM, Concetti F and Lucarini N. Haptoglobin (HP) polymorphisms and human longevity: a cross-sectional association study in a Central Italy population. Clin Chim Acta. 2011; 412:574-577.

15. Gusareva ES, Carrasquillo MM, Bellenguez C, Cuyvers E, Colon S, Graff-Radford NR, Petersen RC, Dickson DW, Mahachie John JM, Bessonov K, Van Broeckhoven C, Consortium G, Harold D, et al. Genome-wide association interaction analysis for Alzheimer's disease. Neurobiol Aging. 2014; 35:2436-2443.

16. Berchtold D, Piccolis M, Chiaruttini N, Riezman I, Riezman H, Roux A, Walther TC and Loewith R. Plasma membrane stress induces relocalization of Slm proteins and activation of TORC2 to promote sphingolipid synthesis. Nat Cell Biol. 2012; 14:542-547.

17. Pierce A, Podlutskaya N, Halloran JJ, Hussong SA, Lin PY, Burbank R, Hart MJ and Galvan V. Over-expression of heat shock factor 1 phenocopies the effect of chronic inhibition of TOR by rapamycin and is sufficient to ameliorate Alzheimer's-like deficits in mice modeling the disease. J Neurochem. 2013; 124:880-893.

18. Powers RW, Kaeberlein M, Caldwell SD, Kennedy BK and Fields S. Extension of chronological life span in yeast by decreased TOR pathway signaling. Genes \& Development. 2006; 20:174-184.

19. Kapahi P, Zid BM, Harper T, Koslover D, Sapin V and Benzer S. Regulation of lifespan in Drosophila by 
modulation of genes in the TOR signaling pathway. Curr Biol. 2004; 14:885-890.

20. Willcox BJ, Donlon TA, He Q, Chen R, Grove JS, Yano $\mathrm{K}$, Masaki KH, Willcox DC, Rodriguez B and Curb JD. FOXO3A genotype is strongly associated with human longevity. Proc Natl Acad Sci U S A. 2008; 105:1398713992.

21. Manolopoulos KN, Klotz LO, Korsten P, Bornstein SR and Barthel A. Linking Alzheimer's disease to insulin resistance: the FoxO response to oxidative stress. Mol Psychiatry. 2010; 15:1046-1052.

22. Clarke R, Peden JF, Hopewell JC, Kyriakou T, Goel A, Heath SC, Parish S, Barlera S, Franzosi MG, Rust S, Bennett D, Silveira A, Malarstig A, et al. Genetic Variants Associated with Lp(a) Lipoprotein Level and Coronary Disease. The New England Journal of Medicine. 2009; 361:2518-2528.

23. Willcox BJ, Tranah GJ, Chen R, Morris BJ, Masaki KH, He Q, Willcox DC, Allsopp RC, Moisyadi S, Poon LW, Rodriguez B, Newman AB, Harris TB, et al. The FoxO3 gene and cause-specific mortality. Aging Cell. 2016; 15.

24. Tan Q, Bathum L, Christiansen L, Benedictis GD, Dahlgaard J, Frizner N, Vach W, Vaupel JW, Yashin AI, Christensen K and Kruse TA. Logistic Regression Models for Polymorphic and Antagonistic Pleiotropic Gene Action on Human Aging and Longevity. Annals of Human Genetics. 2003; 67:598-607.

25. Arai Y, Nakazawa S, Kojima T, Takayama M, Ebihara Y, Shimizu K, Yamamura K, Homma S, Osono Y, Gondo Y, Masui $\mathrm{Y}$, Inagaki $\mathrm{H}$, Kitagawa $\mathrm{K}$, et al. High adiponectin concentration and its role for longevity in female centenarians. Geriatrics \& Gerontology International. 2006; 6(32-39).

26. Miura Y, Hashii N, Tsumoto H, Takakura D, Ohta Y, Abe Y, Arai Y, Kawasaki N, Hirose N, Endo T and Sonic. Change in N-Glycosylation of Plasma Proteins in Japanese Semisupercentenarians. PLoS One. 2015; 10:e0142645.

27. Atzmon G, Pollin TI, Jill Crandall J, Tanner K, Schechter CB, Scherer PE, Rincon M, Siegel G, Katz M, Lipton RB, Shuldiner AR and Barzilai N. Adiponectin Levels and Genotype: A Potential Regulator of Life Span in Humans. The journals of gerontology Series A, Biological sciences. 2008; 63:447-453.

28. Van Cauwenberghe C, Van Broeckhoven C and Sleegers $\mathrm{K}$. The genetic landscape of Alzheimer disease: clinical implications and perspectives. Genet Med. 2015.

29. Barzilai N, Atzmon G, Schechter C, Schaefer EJ, Cupples AL, Lipton R, Cheng $\mathrm{S}$ and Shuldiner AR. Unique lipoprotein phenotype and genotype associated with exceptional longevity. The Journal of the American Medical Association. 2003; 290:2030-2040.

30. Milman S, Atzmon G, Crandall J and Barzilai N. Phenotypes and genotypes of high density lipoprotein cholesterol in exceptional longevity. Current Vascular
Pharmacology. 2014; 12:690-697.

31. Farrer LA, Cupples LA, Haines JL, Hyman B, Kukull WA, Mayeux R, H. Myers RH, Pericak-Vance MA, Risch $\mathrm{N}$, van Duijn CM and Consortium ftAaADMA. Effects of Age, Sex, and Ethnicity on the Association Between Apolipoprotein E Genotype and Alzheimer Disease A Meta-analysis. JAMA. 1997; 278:1349-1356.

32. Liu CC, Kanekiyo T, Xu H and Bu G. Apolipoprotein E and Alzheimer disease: risk, mechanisms and therapy. Nat Rev Neurol. 2013; 9:106-118.

33. Yanagisawa K. Cholesterol and pathological processes in Alzheimer's disease. J Neurosci Res. 2002; 70(3):361-366.

34. Rodrigue KM, Rieck JR, Kennedy KM, Devous MD, Sr., Diaz-Arrastia R and Park DC. Risk factors for beta-amyloid deposition in healthy aging: vascular and genetic effects. JAMA Neurol. 2013; 70:600-606.

35. Thambisety M. Do extracellular chaperone proteins in plasma have potential as Alzheimer's disease biomarkers? Biomarkers in medicine. 2010; 4:831-834.

36. Spagnuolo MS, Maresca B, La Marca V, Carrizzo A, Veronesi C, Cupidi C, Piccoli T, Maletta RG, Bruni AC, Abrescia $\mathrm{P}$ and Cigliano L. Haptoglobin interacts with apolipoprotein $\mathrm{E}$ and beta-amyloid and influences their crosstalk. ACS Chem Neurosci. 2014; 5:837-847.

37. Cocciolo A, Di Domenico F, Coccia R, Fiorini A, Cai J, Pierce WM, Mecocci P, Butterfield DA and Perluigi M. Decreased expression and increased oxidation of plasma haptoglobin in Alzheimer disease: Insights from redox proteomics. Free Radic Biol Med. 2012; 53:1868-1876.

38. Langlois MR and Delanghe JR. Biological and clinical significance of haptoglobin polymorphism in humans. Clinical Chemistry. 1996; 42:1589-1600.

39. De Bacquer D, De Backer D, Langlois M, Delanghe J, Kesteloot $\mathrm{H}$ and Kornitzer M. Haptoglobin polymorphism as a risk factor for coronary heart disease mortality. Atherosclerosis. 2001; 157:161-166.

40. Levy AP, Larson MG, Corey D, Lotan R, Vita JA and Benjamin EJ. Haptoglobin phenotype and prevalent coronary heart disease in the Framingham offspring cohort. Atherosclerosis. 2004; 172:361-365.

41. Simpson M, Snell-Bergeon JK, Kinney GL, Lache O, Miller-Lotan R, Anbinder Y, Rewers MJ and Levy AP. Haptoglobin genotype predicts development of coronary artery calcification in a prospective cohort of patients with type 1 diabetes. Cardiovasc Diabetol. 2011; 10:99.

42. Fortney K, Dobriban E, Garagnani P, Pirazzini C, Monti D, Mari D, Atzmon G, Barzilai N, Franceschi C, Owen AB and Kim SK. Genome-Wide Scan Informed by Age-Related Disease Identifies Loci for Exceptional Human Longevity. PLoS Genet. 2015; $11:$ e1005728.

43. Erikson GA, Bodian DL, Rueda M, Molparia B, Scott ER, Scott-Van Zeeland AA, Topol SE, Wineinger NE, Niederhuber JE, Topol EJ and Torkamani A. WholeGenome Sequencing of a Healthy Aging Cohort. Cell. 
2016; 165:1002-1011.

44. Napolioni V, Gianni P, Carpi FM, Predazzi IM and Lucarini N. APOE haplotypes are associated with human longevity in a Central Italy population: evidence for epistasis with HP 1/2 polymorphism. Clin Chim Acta. 2011; 412:1821-1824.

45. Garasto S, Rose G, Derango F, Berardelli M, Corsonello A, Feraco E, Mari V, Maletta R, Bruni A, Franceschi C, Carotenuto L and De Benedictis G. The Study of APOA1, APOC3 and APOA4 Variability in Healthy Ageing People Reveals Another Paradox in the Oldest Old Subjects. Annals of Human Genetics. 2003; 67:54-62.

46. Huffman DM, Deelen J, Ye K, Bergman A, Slagboom EP, Barzilai N and Atzmon G. Distinguishing between longevity and buffered-deleterious genotypes for exceptional human longevity: the case of the MTP gene. J Gerontol A Biol Sci Med Sci. 2012; 67:1153-1160.
47. Bonafe M, Marchegiani F, Cardelli M, Olivieri F, Cavallone L, Giovagnetti S, Pieri C, Marra M, Antonicelli R, Troiano L, Gueresi P, Passeri G, Berardelli M, et al. Genetic analysis of Paraoxonase (PON1) locus reveals an increased frequency of Arg192 allele in centenarians. Eur J Hum Genet. 2002; 10:292-296.

48. Atzmon G, Rincon M, Schechter CB, Shuldiner AR, Lipton RB, Bergman A and Barzilai N. Lipoprotein genotype and conserved pathway for exceptional longevity in humans. PLoS Biol. 2006; 4:e113.

49. Tan Q, Soerensen M, Kruse TA, Christensen K and Christiansen L. A novel permutation test for case-only analysis identifes epistatic effects on human longevity in the FOXO gene family. Aging Cell. 2013; 12:690-694. 